Original article

\title{
Value of schizophrenia treatment II: Decision modelling for developing early detection and early intervention services in the Czech Republic
}

\author{
Petr Winkler ${ }^{\mathrm{a}, \mathrm{b}, *}$, Hana Marie Broulíkováa,c, Lucie Kondrátováa, Martin Knapp ${ }^{\mathrm{d}}$, \\ Paul Arteel ${ }^{\mathrm{e}}$, Patrice Boyer ${ }^{\mathrm{f}}$, Silvana Galderisi ${ }^{\mathrm{g}}$, Hikka Karkkainen ${ }^{\mathrm{e}}$, Aagje Ieven ${ }^{\mathrm{h}}$, \\ Pavel Mohr ${ }^{\mathrm{a}, \mathrm{i}}$, Danuta Wasserman ${ }^{\mathrm{j}}, \mathrm{A}-$ La Park $^{\mathrm{d}}$, Michella Tinelli ${ }^{\mathrm{d}}$, Wolfgang Gaebel ${ }^{\mathrm{k}}$ \\ ${ }^{a}$ National Institute of Mental Health, Klecany, Czech Republic \\ ${ }^{\mathbf{b}}$ Health Service and Population Research Department, Institute of Psychiatry, Psychology and Neuroscience, King's College London, London, UK \\ ${ }^{\mathrm{c}}$ Department of Statistics and Probability, Faculty of Informatics and Statistics, University of Economics, Prague, Czech Republic \\ ' PSSRU, Department of Health Policy, London School of Economics E Political Science, London, UK \\ e Global Alliance of Mental Illness Advocacy Networks-Europe (GAMIAN Europe), Belgium \\ ${ }^{\mathrm{f}}$ Université Paris Diderot, Paris, France \\ $\mathrm{g}$ University of Campania Luigi Vanvitelli, Naples, Italy \\ ${ }^{\mathrm{h}}$ European Federation of Associations of Families of People with Mental Illness (EUFAMI), Belgium \\ i 3rdFaculty of Medicine, Charles University Prague, Czech Republic \\ ${ }^{\mathbf{j}}$ National Centre for Suicide Research and Prevention of Mental Ill-Health (NASP), Karolinska Institutet, Stockholm, Sweden \\ ${ }^{\mathrm{k}}$ LVR-Klinikum, Department of Psychiatry and Psychotherapy, Medical Faculty, Heinrich-Heine-University, Düsseldorf, Germany
}

\section{A R T I C L E I N F O}

\section{Article history:}

Received 19 April 2018

Received in revised form 18 June 2018

Accepted 25 June 2018

Available online 20 July 2018

\section{Keywords:}

Schizophrenia

Psychosis

Early detection

Early intervention

Health economics

\begin{abstract}
A B S T R A C T
Background: Positive findings on early detection and early intervention services have been consistently reported from many different countries. The aim of this study, conducted within the European Brain Council project "The Value of Treatment", was to estimate costs and the potential cost- savings associated with adopting these services within the context of the Czech mental health care reform.

Methods: Czech epidemiological data, probabilities derived from meta-analyses, and data on costs of mental health services in the Czech Republic were used to populate a decision analytical model. From the health care and societal perspectives, costs associated with health care services and productivity lost were taken into account. One-way sensitivity analyses were conducted to explore the uncertainty around the key parameters.

Results: It was estimated that annual costs associated with care as usual for people with the first episode of psychosis were as high as 46 million Euro in the Czech Republic 2016. These annual costs could be reduced by $25 \%$ if ED services were adopted, $33 \%$ if EI services were adopted, and $40 \%$ if both, ED and EI services, were adopted in the country. Cost-savings would be generated due to decreased hospitalisations and better employment outcomes in people with psychoses.

Conclusions: Adopting early detection and early intervention services in mental health systems based on psychiatric hospitals and with limited access to acute and community care could generate considerable cost- savings. Although the results of this modelling study needs to be taken with caution, early detection and early intervention services are recommended for multi-centre pilot testing accompanied by full economic evaluation in the region of Central and Eastern Europe.
\end{abstract}

(C) 2018 Elsevier Masson SAS. All rights reserved.

\section{Introduction}

Early Detection (ED) and Early intervention (EI) services were developed to provide support shortly before and during the onset of psychosis. These services are currently well-incorporated in

DOI of original article: http://dx.doi.org/10.1016/j.eurpsy.2018.06.007

* Corresponding author at: Department of Social Psychiatry, National Institute of Mental Health, Topolová 748, 250 67, Klecany, Czech Republic.

E-mail addresses: petr.winkler@nudz.cz, petr.winkler@kcl.ac.uk (P. Winkler). mental health policies of some countries, such as the United Kingdom [1,2] where in 2009 they were provided by 145 community teams operating throughout the country [3].

ED services aim to reduce the transition to psychosis or the duration of untreated psychosis (DUP) which is crucial for the illness prognosis and treatment because it significantly affects the severity of symptoms, the risk of relapse, overall functioning as well as the response to treatment [4,5]. ED services use media, public events, and community work to inform about early signs of 
psychoses and facilitate access of young people to mental health care [6]. ED services focus on high risk subjects, i.e. people with prodromal symptoms (attenuated psychotic symptoms, full-blown psychotic symptoms that are brief and self-limiting, or a significant decrease in functioning in the context of genetic risk for schizophrenia) [43]. A number of evaluations of ED programmes have reported the positive outcomes of ED in terms of shortening DUP $[6,7]$.

EI services provide continuous support to people at early stage of psychosis which is usually the first 2 to 5 years from the illness onset. EI services are usually based on a cooperation between a multidisciplinary team (usually including psychiatrist, clinical psychologist, psychiatric nurses and social care workers), general practitioners and families [1] and are built upon various services including case management, pharmacological treatment, psychological (most often cognitive behaviour therapy) and psychosocial interventions (such as supportive counselling or social skills training), family therapy and supported employment services $[2,3]$. Recent meta-analyses showed that EI services have (in comparison to the treatment as usual in a given setting) high potential for decreasing the hospital admission rates [3,8,9], and risk of relapse [3], and lowering the positive and negative symptoms of a severe mental illness [3] as well as the duration of untreated psychosis [10] and suicide risk [11]. At the same time, the recent studies have consistently found the positive impacts of EI on employment and education [8,12].

Furthermore, EI and ED programmes appeared to be costeffective in a longer period of time, usually in two years, especially because of the reductions in the length of stay in hospitals and lost productivity [11,13-16]. However, a study from Denmark found the effect of EI services was not sustainable in a 5-year follow-up [17]. Also, the analysis of patient journey presented in this issue [18] showed the identification of early symptoms and the provision of timely intervention as one of the key drivers towards better outcomes and recovery in patients with schizophrenia.

However, ED and EI services are mostly unavailable in the countries of Central and Eastern Europe and currently there is no formal evidence to support such an investment. Mental health care systems in this region are predominantly hospital-based and community services are not available to those who in need [19]. This leads to excessively long hospitalisations, exceeding 20 years in some cases and being over 100 days long on average [20,21]. Central and Eastern Europe is also a region with high mortality rates among people with mental disorders, high suicide rates, excessive alcohol consumption, and high level of public stigma [19,22-24]. Severe lack of health service and population research in psychiatry leads to decision-making not being based on evidence, which imposes a risk that already scarce resources are spent ineffectively $[19,25]$. It has been also repeatedly observed that institutionalization of people with mental disorders in regional psychiatric hospitals is often associated with nonadherence to human rights of people with disabilities [26].

Current mental health care reforms in the Czech Republic is focused on deinstitutionalization, destigmatization, improving the quality of care, and strengthening the evidence based mental health care development with the overall aim to improve the quality of life of people with mental health problems [27]. Deinstitutionalization is considered to be a priority as it has been demonstrated to be preferred by patients and to improve the quality of life of people with severe mental illnesses while not leading to homelessness, crime, and suicidal behaviours [28-30]. Economic case for deinstitutionalization has also been made, and it has been suggested that community care is not more costly when the quality of care is taken into account [31,32]. ED and EI services could be developed within the pursuit of mental health care reforms in CEE as they enable people with incipient psychosis to stay in the community and out of the psychiatric hospitals, and therefore are complementary to deinstitutionalization. In this paper, we aim to show the cost estimates based on an economic model for ED and EI services in the Czech Republic.

\section{Methods}

This study is a follow-up to the EBC initiatives which estimated a burden and costs associated with disorders of the brain in Europe in 2005 and in 2010 [33-37]. The current EBC project was entitled "Value of Treatment" and its aims were to identify gaps in the current health care systems across Europe, and to estimate the value of addressing these gaps. Study by Mohr et al. [18] focused on journeys of patients with schizophrenia and identified a substantial gap in early detection and early intervention services, which result in both, missed or delayed diagnosis and a limited access to timely and adequate treatments. The present study focused on modelling cost-consequences of tackling these problems in the Czech Republic.

Decision analytical modelling is a systematic approach to inform decisions under uncertainty via defining a set of possible consequences of alternative actions [38]. We used a decision tree as a vehicle to estimate costs associated with adopting ED and EI services in the Czech Republic as it allowed us to model economic consequences of the alternative actions in the absence of direct local evidence on (cost-)effectiveness of ED and EI. In our case, the alternative actions were a) to do nothing, b) to introduce early detection services, c) to introduce early intervention services, and d) to introduce both, early detection and early intervention services for psychoses as defined by ICD-10's F20-F29 codes. The target population of these services are young people experiencing first symptoms or first episode of psychoses (FEP) in the Czech Republic. The option a) refers to the treatment as usual (TAU) which is currently comprised of a treatment at outpatient settings, delivered by a psychiatrist which is usually limited to prescription of psychopharmaceuticals, a treatment in psychiatric hospitals, and rarely also assertive community treatment. From a societal perspective, however, we focused only on costs related to health and social care services and productivity lost, and excluded other costs for informal care or criminal justice system.

As described in detail below, our model relies on three sources of data: a) epidemiological data are based on the Czech all-cause hospitalizations register which was described in more detail in our previous studies [20,39]; b) probabilities were taken from metaanalyses which were identified via our meta-review (i.e. systematic review of systematic reviews and meta-analyses); c) costs based on Czech unit costs and experiences of EI and ED teams in south London.

\subsection{Probabilities and epidemiological data}

The key assumption is that international data would reasonably apply in the Czech context. This is a strong but necessary assumption in the absence of any local evidence based on Czech experience. To identify the best available international evidence on transition probabilities possible that would enter our model, we performed review of systematic reviews and meta-analyses (or meta-review). We have systematically searched the Web of Science, Medline, EMBASE and Cochrane Library to identify meta-analyses on ED and EI services. The following strategy was used for the Web of Science and translated to other databases: TOPIC: (early interven* or early diagnos* or early detect*) AND TOPIC: (mental health or mental disorder or mental illness or mental disease) AND TOPIC: (review or literature search or systematic review or meta-analysis or meta analysis) NOT TOPIC: (Alzheimer or Alzheimer's or autism or dementia or cardiovascular 
or PTSD or postpartum or eating or cancer). The full strategy is available in the Appendix 1.

Further assupmtions were as follows: People with FEP were defined as those with a first hospitalization for psychotic symptoms. There were 5478 of people with psychotic disorders hospitalized for the first time at a psychiatric outpatient care service in the Czech Republic in 2015 (i.e. in a period between $1^{\text {st }}$ January 2015 and $31^{\text {st }}$ December 2015) [40]. According to a metaanalysis, the risk of transition to psychosis among the high-risk group, which is a potential target of ED services, is 0.22 [41]. Another recent meta-analysis demonstrated that ED services reduce the risk of transition to psychosis in the high-risk group by $54 \%$ [42].

If there were EI services available for people who made the transition from the high-risk group to FEP, the probability of hospitalization was estimated to drop from 0.74 to 0.52 , which is based on the meta-analysis by Randall, Vokey [43], and the probability of retaining employment would increase from 0.29 to 0.61 , which is based on meta-analysis by Bond, Drake [12].

\subsection{Costs}

The associated annual costs were calculated as follows. The cost of unemployment was assumed to be equal to the minimal Czech wage. The costs of ED services were estimated by assuming that the Czech ED and EI teams would have the same composition as they have in UK $[14,44,45]$. The costs of ED were calculated by using costs of ED services per patient in the first year of the service provision. It was also assumed that one Czech EI team would be able to take care of 150 clients a year which is in line with experiences EI services in the UK [47] and Denmark [48,49]

Czech unit costs were used to calculate overall costs of both, Czech EI and Czech ED team. The costs of treatment as usual was calculated as costs for:

i) outpatient psychiatrist (highly specialized services provided exclusively by psychiatrists and mostly limited to quick assessment of the patient and drug prescription)- these costs were based on the average consumption of this services among the sample of 138 patients who were followed-up in the community services for a 12 -month period;

ii) inpatient care- these costs were based on the average length of hospital stay for the people with psychoses in the Czech Republic and on the related unit costs of one day of inpatient care service (including the costs for an overnights stay); iii) Psychiatric medications- these costs were estimated as an average consumption of psychopharmaceuticals by clients of OASIS team [14] and costs of the corresponding psychopharmaceuticals in $\mathrm{CZ}$ as reported by the State Institute for Drug Control.

These costs were combined using the following formula: = yearly consumption of psychopharmaceuticals + yearly consumption of services of an outpatient psychiatrist + (cost of inpatient care per day ${ }^{*}$ average length of stay in inpatient psychiatric hospitals in $\mathrm{CZ}$ - average length of stay in inpatient psychiatric hospitals in $\mathrm{CZ} *$ costs of outpatient psychiatrist) ${ }^{*}$ probability of being inpatiently hospitalized.

All costs were converted to Euro in 2016 prices, with an exchange rate $27 \mathrm{CZK}$ per 1 Euro. All costs, data and probabilities are reported in the Table 1.

\subsection{Sensitivity analysis}

One- way sensitivity analyses were performed for anumber of key parameters, including sensitivity analysis for both, the median (rather than minimum) wage rate for the age group of 20-29 years which is when FEP usually occurs. Sensitivity analyses were also focused on shorter than average length of inpatient hospitalization for psychosis in the Czech Republic, because it might be assumed that the inpatient stay of people with FEP could be shorter than inpatient stay of those with chronic psychoses [50]. Otherwise, each of the probabilities employed in the model was modified to explore all the possible uncertainties.

\section{Results}

Based on the data from the Czech registries [40] and probabilities derived from the meta-analysis by Fusar-Poli, Bonoldi [41] we estimated that there were 24,900 people with high risk of developing psychosis in CZ 2015. Considering the effects of ED programmes as estimated in the meta-analysis by van der Gaag, Smit [42] we estimated that if the ED services were available to everyone in the Czech Republic, the number of people hospitalized with psychosis for the first time could have dropped from 5478 to 2520. Taking further into account the effectsof EI services as assessed in meta-analysis by Randall, Vokey [43], out of the total 2520 (or 5478 if there were no ED services) people with the FEP, 1310 (or 2849) would be hospitalised and 1537 (or 3342) would retain their employment if there were EI services available in the

Table 1

Parameters and costs used within the model.

\begin{tabular}{|c|c|c|c|c|}
\hline Parameters & Value & \multicolumn{2}{|c|}{ Source - reference } & Source - type \\
\hline New cases of psychosis in the Czech Republic 2015 & 5478 & \multicolumn{2}{|c|}{ Unpublished, NIMH CZ } & Czech register data \\
\hline Transition to psychosis at those at high risk in 1 year & 0.22 & \multicolumn{2}{|c|}{ Fusar-Poli et al. [41] } & Meta-analysis \\
\hline Early detection - reduction of transition to psychosis at those at high risk (54\%) & 0.10 & \multicolumn{2}{|c|}{ van der Gaag et al. [42] } & Meta-analysis \\
\hline Probability of employment while receiving EI services & 0.61 & \multicolumn{2}{|c|}{ Bond et al. [12] } & Meta-analysis \\
\hline Probability of employment while not receiving EI services & 0.29 & \multicolumn{2}{|c|}{ Bond et al. [12] } & Meta-analysis \\
\hline Probability of hospitalization - a - with EI & 0.52 & \multicolumn{2}{|c|}{ Randall et al. $[9,43]$, } & Meta-analysis \\
\hline Probability of hospitalization - a - no EI & 0.74 & \multicolumn{2}{|c|}{ Randall et al. $[9,43]$} & Meta-analysis \\
\hline Costs & \multicolumn{2}{|c|}{ Value in EUR per person per year } & Source - reference & Source type \\
\hline Cost of Early Detection service package - CZ - calculated using Czech unit costs & \multicolumn{2}{|l|}{514} & Valmaggia et al. [14] & UK RCT \\
\hline Cost of Early Intervention service package - CZ - calculated using Czech unit costs & \multicolumn{2}{|l|}{1797} & Park et al. [44] & UK RCT \\
\hline Cost of treatment as usual $-\mathrm{CZ}$ & \multicolumn{2}{|l|}{4925.61} & Unpublished, NIMH CZ & $\mathrm{CZ}$ unit costs (UC) \\
\hline Cost of hospitalization for inpatient day - CZ & \multicolumn{2}{|l|}{55} & Unpublished, NIMH CZ & CZ UC \\
\hline Median annual wage for the age group $20-29$ in $\mathrm{CZ}$ & \multicolumn{2}{|l|}{10113} & MLSA, 2017 [59] & National statistics \\
\hline Minimal annual wage in $\mathrm{CZ}$ & \multicolumn{2}{|l|}{4889} & MLSA, 2017 [60] & National statistics \\
\hline Costs of OASIS assessment & \multicolumn{2}{|l|}{31} & Valmaggia et al. [14] & UK RCT, CZ UC \\
\hline
\end{tabular}


country. If there were no EI services, then 1865 (or 4054) would be hospitalised and 731 (or 1589) would retain their employment.

The economic model demonstrated that costs associated with the above-mentioned scenarios are as follows. The costs of care as usual for people with FEP are estimated to be as high as 46 million Euro each year. These estimates are conservative in terms of that only health care costs and costs associated with reduced productivity, and not costs associated with other sectors, such as social care, informal care, criminal justice and others, were taken into account. It is also estimated that these costs could be reduced by $25 \%$ if ED services were adopted (policy change 1 ), $33 \%$ if EI services were adopted (policy change 2), and $40 \%$ if both, ED and EI services, were adopted (policy change 3 ) in the country (Fig. 1). This means cost savings of about 2,000-2,800-3,200 Euro per patient when introducing policy changes 1-2-3 respectively.

Sensitivity analyses demonstrated that the estimates are robust, and that only dramatically decreased effect of ED services would have influenced the overall results. Meta-analyses used in our model demonstrated the 54\% reduction in transition to psychosis was associated with ED services, only if this effect would drop to approximately $30 \%$ if ED services would introduce additional costs to the Czech mental health care system (Fig. 2a, $\mathrm{b}$, and $\mathrm{c})$.

\section{Discussion}

The economic model presented in this paper suggests that adopting ED and EI services in the Czech Republic would be a costsaving strategy for its mental health care development. This is an important finding because mental health care systems in the region are expected to transform from hospital-based towards more community-oriented ones in the near future. ED and EI centres, such as the EPPIC (Early Psychosis Prevention and Intervention Centre) in Australia, were developed in many countries globally as an alternative to hospitalisation [51], and could serve as a good example to benchmark when reforming mental health care systems in the region of Central and Eastern Europe.
The economic evidence on ED and EI services is quite extensive and comes from many different cultural backgrounds [11,1416,44]. A focus on reducing the duration of untreated psychosis (DUP) has been demonstrated to lead to better outcomes such as fewer and shorter hospital stays of people with psychosis [51]. However, the evidence is not unanimous. Large trial in northern Italy tested multicomponent intervention added to the usual community based services for people with FEP [52]. Despite the significant improvements in symptoms, global functioning, and other outcomes, this study did not find a significant reduction in neither, number of hospital admissions nor length of inpatient stays among patients in the active group, compared to the control group [53]. It can be interpreted that this might be partly explained by a good-quality community care which already existed in the area and which was considered as the treatment as usual. Also, a stronger emphasis on early detection might have led to a reduced number of days in hospitalization in the intervention group. As there is a severe lack of community services in the region of CEE [19], we assume that adopting ED and EI services in the region might mimic the effectiveness of these services as demonstrated in the meta-analyses used for populating decision tree in this modelling study. The adoption and implementation should be conducted carefully, fidelity should be ensured and evaluation well planned and rigorously conducted, because the results will influence mental health care development in the region - if negative they will hinder further reforms, if positive they will help to justify further system changes to general public [54]. Strengths and limitations

The strengths of our model stem from the quality of data that we had available. First, our epidemiological data are based on the Czech national registers which reflect the current situation in health-care utilization. Second, all cost data are based on thorough calculations of Czech unit costs that were conducted by our team in collaboration with local health and social care providers. Third, all probabilities used within the model come from robust metaanalyses which were published quite recently and identified via meta-review.

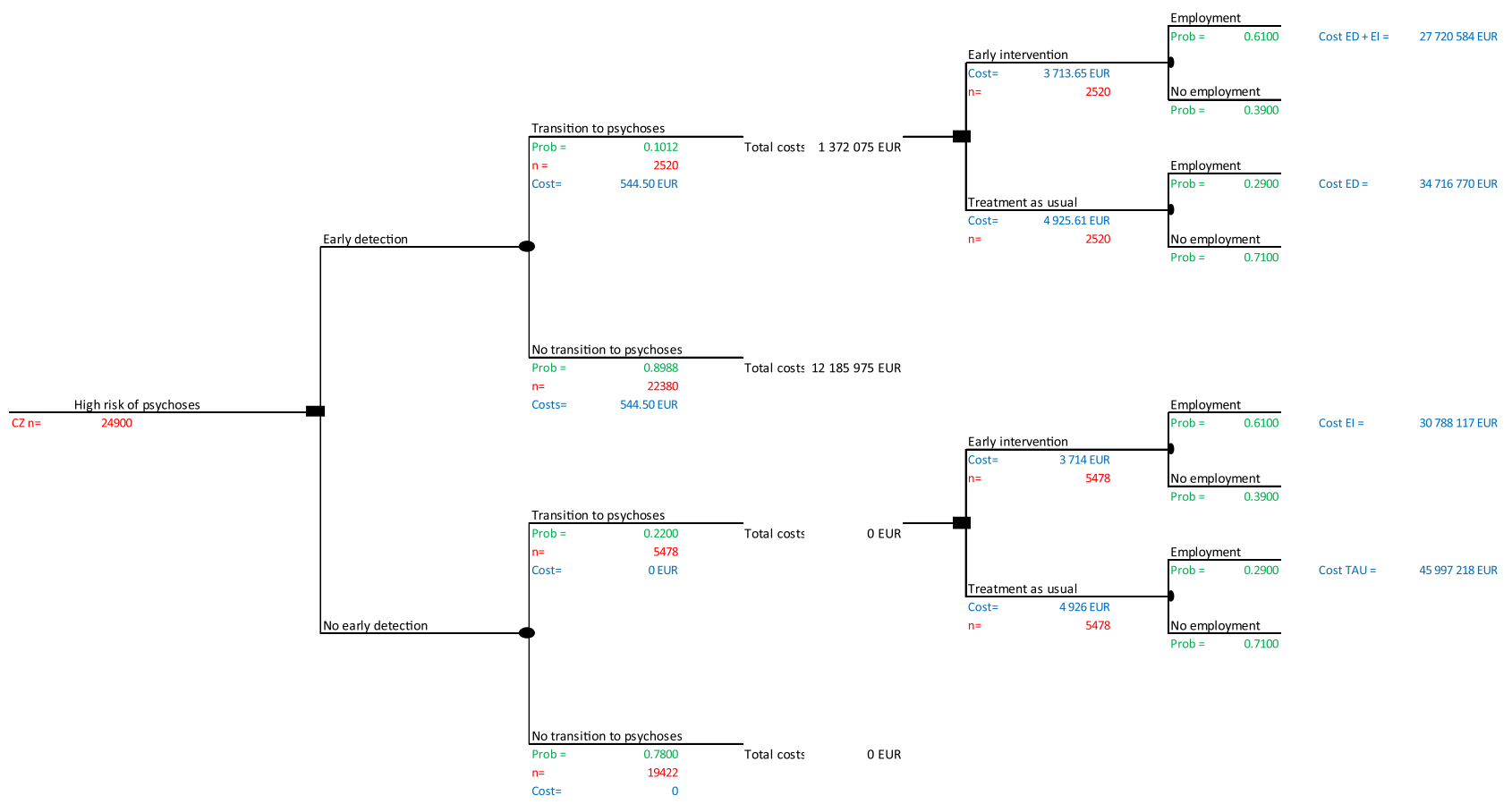

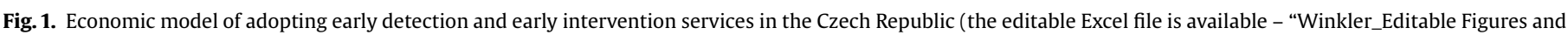
Tables"). 
A

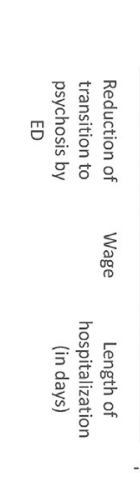

Sensitivity Analysis for Early Detection

Baseline Savings (mil EUR)

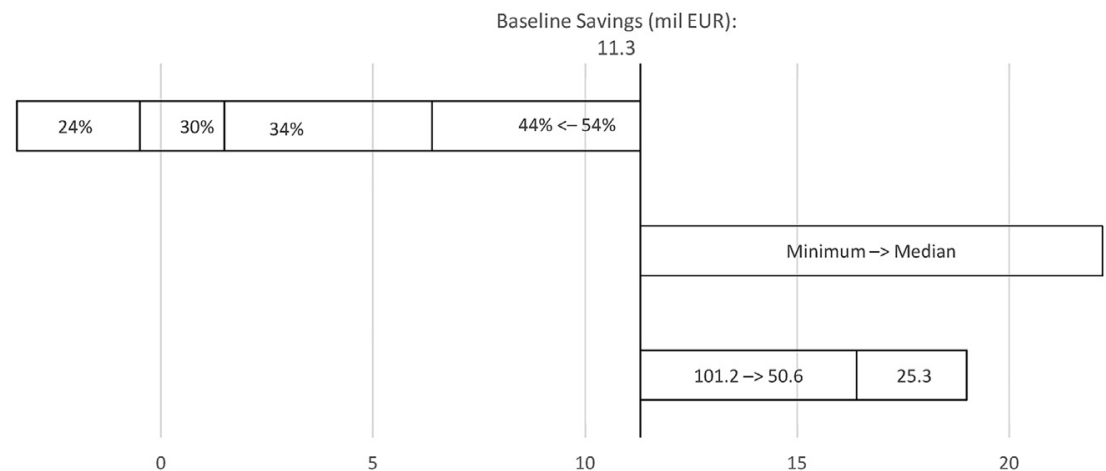

15

B

Sensitivity Analysis for Early Intervention

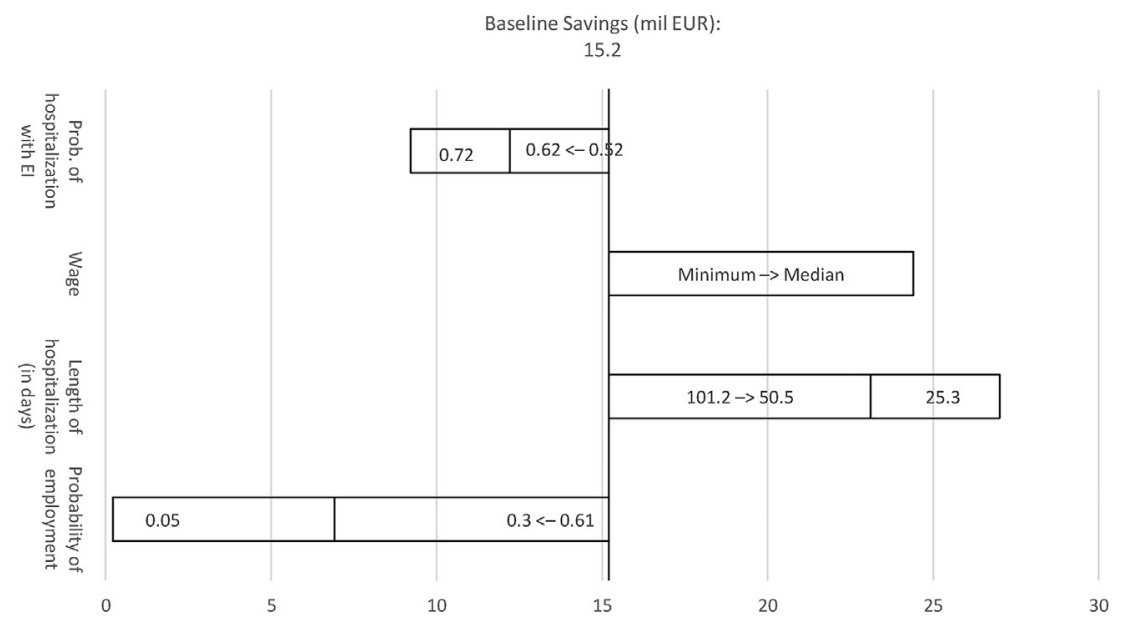

C Sensitivity Analysis for Early Detection and Intervention
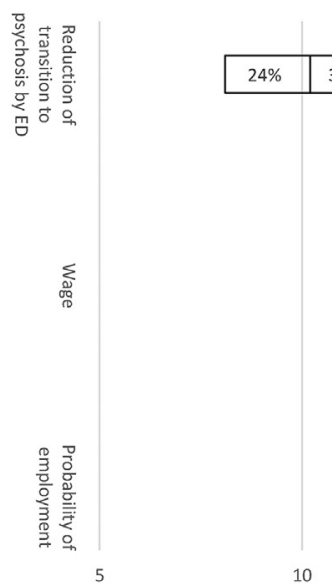

10

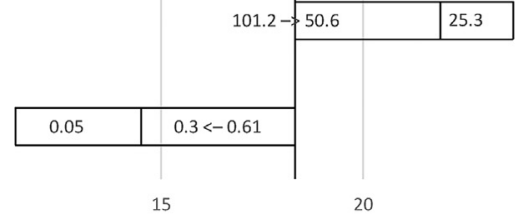

Baseline Savings (mil EUR):

20

25

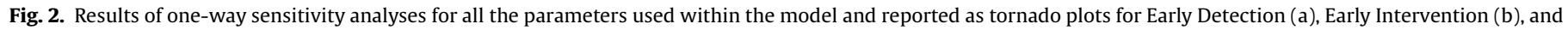
Early Detection and Early Intervention (c). The editable Excel file is available ("Winkler_Editable Figures and Tables"). 
However, this study has a number of limitations. First and foremost, neither, ED nor EI teams, has ever operated in the Czech Republic, which is why we had to rely on meta-analysis rather than Czech specific data that would come from local services. Also, we relied on the assumption that the services would perform at least as good as reported by meta-analyses used in our model. This might not be necessarily true and, for instance, employment services could have different effects due to different legal and work environments in the Czech Republic. However, we did use sensitivity analyses to explore this and it has been demonstrated that ED and EI services would be cost-saving even if we would reduce the probability of employment from 0.61 to 0.05 (Figure 2abc).

The other characteristic of our model is that we assumed a perfect scenario and ED and EI were available to all people who are currently hospitalized in the Czech Republic with FEP. This means that the services would have to immediately have the same availability as outpatient psychiatrists in the Czech Republic. This would be ideal, but of course, achievable only in a longer time horizon. Furthermore, we did include neither, extra costs for setting up the early detection and early intervention services in the Czech Republic nor capital costs (costs of new or existing buildings and equipment). The earlier would mean higher costs for early detection and early intervention services in the first year of functioning, and the latter would (at least in long-term) not significantly change the differences in costs as an increase in capital costs for new services would be offset by decrease in capital costs for treatment as usual.

On the other hand our estimates might be considered conservative in a sense that only health care and employment related costs were included in the model. The cost savings could be much higher if we had been able to include also costs related to criminal justice, informal care and alike.

\section{Conclusions}

This study adds an economic argument to the analysis of schizophrenia patient journey [18]. Our results suggest that adopting ED and EI services in the Czech Republic would be cost saving due to decreases in hospitalisations and better employment outcomes of people with psychoses. These findings are in line with other studies conducted in England, Denmark, Australia and elsewhere [11,14-16,44] but have more informative value for the hospital-based systems in the region of Central and Eastern Europe where the development of mental health care has been hindered by a lack of epidemiological and economic evidence. The current mental health care reform in the Czech Republic utilizes European Structural and Investment Funds to finance the first phase of the reform. It is a unique opportunity which might become an example for other countries in the region because Ministry of Health of the Czech Republic, for the first time since the dissolution of communism more than a quarter of century ago, has fully committed to transform the mental health care system in a way which has been repeatedly suggested by both, mental health professionals and international organizations $[55,56]$. The results of our decision model, however, have to be taken with caution and full economic evaluations (cost-effectiveness and cost-utility analyses) alongside multi-centre trials are recommended before scaling up ED and EI services in those European countries where these services are still not available $[57,58]$. Czech Republic now intends to conduct such a study within the ongoing national mental health care reform; economic evidence generated within the forthcoming study might be decisive for policy and practice in the country.

\section{Declarations of interest}

None.

\section{Funding}

This work on schizophrenia is part of a series of case studies covering nine neurological and psychiatric conditions, conducted within the "Value of Treatment for Brain Disorders" research project of the European Brain Council. PM and PW were supported by the Ministry of Education, Youth and Sports of the Czech Republic (project NPU4NUDZ: LO1611); PM was also supported by the Ministry of Health of the Czech Republic (grant No. AZV 1528998A).

\section{Acknowledgement}

We thank to Leonardo Koeser for thoughtful discussions on the design of analyses.

\section{References}

[1] NICE. Implementing the early intervention in psychosis access and waiting time standard: guidance. UK: NHS England: The National Collaborating Centre for Mental Health and the National Institute for Health and Care Excellence; 2016.

[2] Garety PA, Craig TK, Dunn G, Fornells-Ambrojo M, Colbert S, Rahaman N, et al. Specialised care for early psychosis: symptoms, social functioning and patient satisfaction. Br J Psychiatry 2006;188:37-45.

[3] Bird V, Premkumar P, Kendall T, Whittington C, Mitchell J, Kuipers E. Early intervention services, cognitive-behavioural therapy and family intervention in early psychosis: systematic review. Br J Psychiatry 2010;197:350-6.

[4] Marshall M, Lewis S, Lockwood A, Drake R, Jones P, Croudace T. Association between duration of untreated psychosis and outcome in cohorts of firstepisode patients: a systematic review. Arch Gen Psychiatry 2005;62:975-83.

[5] Perkins DO, Gu H, Boteva K, Lieberman JA. Relationship between duration of untreated psychosis and outcome in first-episode schizophrenia: a critical review and meta-analysis. Am Psychiatry 2005;162:1785-804.

[6] Johannessen JO, McGlashan TH, Larsen TK, Horneland M, Joa I, Mardal S, et al. Early detection strategies for untreated first-episode psychosis. Schizophr Res 2001;51:39-46.

[7] Lloyd-Evans B, Crosby M, Stockton S, Pilling S, Hobbs L, Hinton M, et al. Initiatives to shorten duration of untreated psychosis: systematic review. $\mathrm{Br} \mathrm{J}$ Psychiatry 2011;198:256-63.

[8] Marshall M, Rathbone J. Early intervention for psychosis. Cochrane database of systematic reviews. John Wiley \& Sons, Ltd; 2011.

[9] Randall JR, Vokey S, Loewen H, Martens PJ, Brownell M, Katz A, et al. A systematic review of the effect of early interventions for psychosis on the usage of inpatient services. Schizophr Bull 2015;41:1379-86.

[10] Larsen TK, Melle I, Auestad B, Haahr U, Joa I, Johannessen JO, et al. Early detection of psychosis: positive effects on 5-year outcome. Psychol Med 2011;41:1461-9.

[11] McCrone P, Park A-L, Knapp M. Economic evaluation of early intervention (EI) services: phase IV report. 2010.

[12] Bond G, Drake R, Luciano A. Employment and educational outcomes in early intervention programmes for early psychosis: a systematic review. Epidemiol Psychiat Sci 2015;24:446-57.

[13] Andrew A, Knapp M, McCrone PR, Parsonage M, Trachtenberg M. Effective interventions in schizophrenia: the economic case. London, UK: Personal Social Services Research Unit, London School of Economics and Political Science; 2012.

[14] Valmaggia L, McCrone P, Knapp M, Woolley J, Broome MR, Tabraham P, et al. Economic impact of early intervention in people at high risk of psychosis. Psychol Med 2009;39:1617-26.

[15] Hastrup LH, Kronborg C, Bertelsen M, Jeppesen P, Jorgensen P, Petersen L, et al. Cost-effectiveness of early intervention in first-episode psychosis: economic evaluation of a randomised controlled trial (the OPUS study). Br J Psychiatry 2013;202:35-41.

[16] Mihalopoulos C, Harris M, Henry L, Harrigan S, McGorry P. Is early intervention in psychosis cost-effective over the long term? Schizophr Bull 2009;35:90918.

[17] Bertelsen M, Jeppesen P, Petersen L, Thorup A, Øhlenschlæger J, le Quach P, et al. Five-year follow-up of a randomized multicenter trial of intensive early intervention vs standard treatment for patients with a first episode of psychotic illness: the OPUS trial. Arch Gen Psychiatry 2008;65:762-71.

[18] Mohr P, Galderisi S, Boyer P, Wasserman D, Arteel P, Ieven A, et al. Value of schizophrenia treatment I: the patient journey. Eur Psychiatry 2018; 53:107-15. 
[19] Winkler P, Krupchanka D, Roberts T, Kondratova L, Machù V, Höschl C, et al. A blind spot on the global mental health map: a scoping review of 25 years' development of mental health care for people with severe mental illnesses in central and eastern Europe. Lancet Psychiat 2017;4(8):634-42.

[20] Winkler P, Mladá K, Krupchanka D, Agius M, Ray MK, Höschl C. Long-term hospitalizations for schizophrenia in the Czech Republic 1998-2012. Schizophr Res. 2016;175:180-5.

[21] IHIS. Psychiatrická péče 2013. [Psychiatric care 2013]. Prague: Institute of Health Information and Statistics of the Czech Republic; 2014.

[22] Krupchanka D, Mladá K, Winkler P, Khazaal Y, Albanese E. Mortality in people with mental disorders in the Czech Republic: a nationwide, register-based cohort study. Lancet Public Health 2018;3:e289-95.

[23] Winkler P, Csemy L, Janouskova M, Mlada K, Motlova LB, Evans-Lacko S. Reported and intended behaviour towards those with mental health problems in the Czech Republic and England. Eur Psychiatry 2015;30:801-6.

[24] Winkler P, Mladá K, Janoušková M, Weissová A, Tušková E, Csémy L, et al. Attitudes towards the people with mental illness: comparison between Czech medical doctors and general population. Soc Psychiatry Psychiatric Epidemiol. 2016;1-9.

[25] WHO. Culture and reform of mental health care in central and eastern Europe Copenhagen. [135_TD\$DIFF]World Health Organization; 2018.

[26] WHO. Mental health, human rights and standards of care: assessment of the quality of institutional care for adults with psychosocial and intellectual disabilities in the WHO European region Copenhagen. [136_TD\$DIFF]World Health Organization; 2018.

[27] MHCZ. In: Health Mo, editor. Reforma péče o duševní zdraví: Strategie reformy psychiatrické péče [Mental health care reform: strategy]. Prague: Ministry of Health, Czech Republic; 2013.

[28] Kunitoh N. From hospital to the community: the influence of deinstitutionalization on discharged long-stay psychiatric patients. Psychiatry Clin Neurosci 2013;67:384-96.

[29] Winkler P, Barrett B, McCrone P, Csémy L, Janoušková M, Höschl C. Deinstitutionalised patients, homelessness and imprisonment: systematic review. Br J Psychiatry 2016;208:421-8.

[30] Henderson C, Phelan M, Loftus L, Dall'Agnola R, Ruggeri M. Comparison of patient satisfaction with community-based vs. Hospital psychiatric services. Acta Psychiatr Scand 1999;99:188-95.

[31] Mansell J, Knapp M, Beadle-Brown J, Beecham J. Deinstitutionalisation and community living-outcomes and costs: report of a European study, Vol. 2. University of Kent; 2007 Main Report.

[32] Knapp M, Beecham J, McDaid D, Matosevic T, Smith M. The economic consequences of deinstitutionalisation of mental health services: lessons from a systematic review of European experience. Health Soc Care Commun 2011;19:113-25

[33] Andlin-Sobocki P, Jönsson B, Wittchen HU, Olesen J. Cost of disorders of the brain in Europe. Eur J Neurol 2005;12:1-27.

[34] Olesen J, Gustavsson A, Svensson M, Wittchen HU, Jönsson B. The economic cost of brain disorders in Europe. Eur J Neurol 2012;19:155-62.

[35] Wittchen H-U, Jacobi F. Size and burden of mental disorders in Europe-a critical review and appraisal of 27 studies. Eur Neuropsychopharm 2005; 15:357-76.

[36] Wittchen H-U, Jacobi F, Rehm J, Gustavsson A, Svensson M, Jönsson B, et al. The size and burden of mental disorders and other disorders of the brain in Europe 2010. Eur Neuropsychopharm 2011;21:655-79.

[37] Gustavsson A, Svensson M, Jacobi F, Allgulander C, Alonso J, Beghi E, et al. Cost of disorders of the brain in Europe 2010. Eur Neuropsychopharmacol 2011:21:718-79.

[38] Briggs AH, Claxton K, Sculpher MJ. Decision modelling for health economic evaluation. USA: Oxford University Press; 2006.

[39] Winkler P, Mladá K, Csémy L, Nechanská B, Höschl C. Suicides following inpatient psychiatric hospitalization: a nationwide case control study. J Affect Disorders 2015; 184:164-9.
[40] IHIS. Psychiatrická péče [Psychiatric Care]. Prague: Institute of Health Information and Statistics of the Czech Republic; 2017.

[41] Fusar-Poli P, Bonoldi I, Yung AR, Borgwardt S, Kempton MJ, Valmaggia L, et al. Predicting psychosis: meta-analysis of transition outcomes in individuals at high clinical risk. Arch Gen Psychiatry 2012;69:220-9.

[42] van der Gaag M, Smit F, Bechdolf A, French P, Linszen DH, Yung AR, et al Preventing a first episode of psychosis: meta-analysis of randomized controlled prevention trials of 12 month and longer-term follow-ups. Schizophr Res 2013;149:56-62.

[43] Randall JR, Vokey S, Loewen H, Martens PJ, Brownell M, Katz A, et al. A systematic review of the effect of early interventions for psychosis on the usage of inpatient services. Schizophr Bull 2015;sbv016.

[44] Park AL, McCrone P, Knapp M. Early intervention for first-episode psychosis: broadening the scope of economic estimates. Early Interv Psychia. 2016;10:144-51.

[45] Craig TK, Garety P, Power P, Rahaman N, Colbert S, Fornells-Ambrojo M, et al. The Lambeth early onset (LEO) team: randomised controlled trial of the effectiveness of specialised care for early psychosis. BMJ 2004;329:1067.

[47] Power P, McGuire P, Iacoponi E, Garety P, Morris E, Valmaggia L, et al. Lambeth early onset (LEO) and outreach \& support in south London (OASIS) service. Early Interv Psychiatry 2007;1:97-103.

[48] Nordentoft M, Thorup A, Petersen L, Øhlenschlæger J, Christensen TØ, Krarup $G$, et al. Does a detection team shorten duration of untreated psychosis? Early Interv Psychiatry 2008;2:22-6.

[49] Petersen L, Jeppesen P, Thorup A, Abel M-B, Øhlenschlæger J, Christensen TØ, et al. A randomised multicentre trial of integrated versus standard treatment for patients with a first episode of psychotic illness. BMJ 2005;331:602.

[50] Huntley DA, Cho DW, Christman J, Csernansky JG. Predicting length of stay in an acute psychiatric hospital. Psychiatry Serv 1998;49(8):1049-53.

[51] McGorry PD. Early intervention in psychosis: obvious, effective, overdue. J Nerv Ment Dis 2015;203:310-8.

[52] Ruggeri M, Bonetto C, Lasalvia A, De Girolamo G, Fioritti A, Rucci P, et al. A multi-element psychosocial intervention for early psychosis (GET UP PIANO TRIAL) conducted in a catchment area of 10 million inhabitants: study protocol for a pragmatic cluster randomized controlled trial. Trials 2012;13:73.

[53] Ruggeri M, Bonetto C, Lasalvia A, Fioritti A, De Girolamo G, Santonastaso P, et al. Feasibility and effectiveness of a multi-element psychosocial intervention for first-episode psychosis: results from the cluster-randomized controlled GET UP PIANO trial in a catchment area of 10 million inhabitants. Schizophr Bull 2015;41:1192-203.

[54] Ruggeri M, Tansella M. New perspectives in the psychotherapy of psychoses at onset: evidence, effectiveness, flexibility, and fidelity: nuove prospettive per la psicoterapia dell'esordio psicotico: fra evidenze, efficacia nella pratica, flessibilità e fidelity. Epidemiol Psych Sci. 2011;20:107-11.

[55] Pěč O. Mental health reforms in the Czech Republic. BJPsych Int 2018;1-3.

[56] Höschl C, Winkler P, Pěč O. The state of psychiatry in the Czech Republic. Int Rev Psychiatry 2012;24:278-85.

[57] Maric NP, Raballo A, Kuzman MR, Petrovic SA, Klosterkötter J, Riecher-Rössler A. European status and perspectives on early detection and intervention in atrisk mental state and first episode psychosis: viewpoint from the EPA section for prevention of mental disorders. Eur Psychiatry 2017;46:48-50.

[58] Maric NP, Petrovic SA, Raballo A, Rojnic-Kuzman M, Klosterkötter J, RiecherRössler A. Survey of the European Psychiatric Association on the European status and perspectives in early detection and intervention in at-risk mental state and first-episode psychosis. Early Interv Psychiatry 2018, doi:http://dx. doi.org/10.1111/eip.12682.

[59] MLSA. Analysis of earnings and expenditures of Czech houselholds in 2016 and prediction for the next period. Czech Republic: Ministry of Labor and Social Affairs; 2017 available at: https://www.mpsv.cz/files/clanky/30460/ Analyza_rok_2016_text.docx, last accessed: 3 July 2018.

[60] MLSA. Overview of minimal wage development. Czech Republic: Ministry of Labor and Social Affairs; 2017 available at: https://www.mpsv.cz/cs/871 last accessed: 3 July 2018. 